\title{
Gestão de bacias hidrográficas
}

Monica F. A. PORTO e RUBEM LA LAINA PORTO

\section{Introdução}

A

GESTÃO de recursos hídricos baseada no recorte territorial das bacias hidrográficas ganhou força no início dos anos 1990 quando os Princípios de Dublin foram acordados na reunião preparatória à Rio-92. Diz o Princípio n.l que a gestão dos recursos hídricos, para ser efetiva, deve ser integrada e considerar todos os aspectos, físicos, sociais e econômicos. Para que essa integração tenha o foco adequado, sugere-se que a gestão esteja baseada nas bacias hidrográficas (WMO, 1992).

A questão central que deve reger a gestão é a integração dos vários aspectos que interferem no uso dos recursos hídricos e na sua proteção ambiental. A bacia hidrográfica permite essa abordagem integrada, e, diz Yassuda (1993), "a bacia hidrográfica é o palco unitário de interação das águas com o meio físico, o meio biótico e o meio social, econômico e cultural".

Em realidade, bem antes de ter ocorrido esse reconhecimento de princípios amplamente aceitos, várias iniciativas de sucesso na área de gestão de recursos hídricos foram baseadas no recorte geográfico da bacia hidrográfica.

Há experiências registradas sobre tratados de utilização do Rio Danúbio que datam de 1616, o tratado Brasil-Peru sobre a navegação do Rio Amazonas em 1851 e o tratado entre o Brasil e a República das Províncias Unidas do Rio da Prata em 1928, entre outros (Granziera, 2001).

Uma importante experiência na gestão de bacias hidrográficas foi a aprovação, em 1922, pelo Congresso dos Estados Unidos, do pacto do Rio Colorado, o qual decidia sobre a partição da utilização da água do rio entre os Estados que compartilhavam a sua bacia hidrográfica. Esse pacto utilizou, aliás, um conceito muito interessante e atual, que coloca, sob a égide do mesmo processo decisório, territórios com produtividade hídrica elevada (Estados doadores) e territórios com produtividade hídrica menor (Estados recebedores), e a utilização conjunta das águas de um mesmo rio (Grigg, 1991).

Ainda no contexto histórico, é importante destacar a formação do Tennessee Valley Authority em 1933. A agência proposta pelo então presidente Roosevelt deveria cuidar, no contexto de uma bacia hidrográfica que envolve sete Estados, de todos os usos da água do rio. A agência da bacia foi proposta com o fim de gerir navegação, controle de cheias, controle de erosão, reflorestamento, desenvolvimento agrícola e industrial e uso das áreas ribeirinhas (http://www.tva.com)

No Brasil, o reconhecimento da crescente complexidade dos problemas relacionados ao uso da água levou ao estabelecimento, em 1976, de acordo en- 
tre o Ministério das Minas e Energia e o governo do Estado de São Paulo para a melhoria das condições sanitárias das bacias do Alto Tietê e Cubatão. O êxito dessa experiência fez que, em seguida, fosse constituída, em 1978, a figura do Comitê Especial de Estudos Integrados de Bacias Hidrográficas (CEEIBH), e a subseqüente criação de comitês executivos em diversas bacias hidrográficas, como no Paraíba do Sul, no São Francisco e no Ribeira de Iguape. Esses comitês tinham apenas atribuições consultivas, nada obrigando a implantação de suas decisões, e dele participavam apenas órgãos do governo. Mesmo assim, constituíram-se em experiências importantes e foram importantes embriões para a evolução futura da gestão por bacia hidrográfica.

A Conferência de Mar del Plata, a primeira organizada pelas Nações Unidas sobre o tema água, recomendou aos Estados-membro que fossem criadas entidades para administrar bacias hidrográficas, a fim de permitir melhor planejamento integrado dos recursos hídricos (Dourojeanni, 1997).

Várias experiências baseadas na gestão de bacias hidrográficas surgem na década de 1980. No Estado do Espírito Santo, é constituído o primeiro Consórcio Intermunicipal Santa Maria/Jucu, de maneira a facilitar a negociação entre usuários, num período seco naquele Estado, e, portanto, com dificuldades de gerir seus conflitos.

Surgem, em 1988, os Comitês das Bacias Sinos e Gravataí, afluentes do Guaíba no Estado do Rio Grande do Sul, que se constituem em iniciativas pioneiras por terem surgido da própria comunidade das bacias hidrográficas, com o apoio do governo do Estado. Apesar de na sua origem esses comitês terem surgido apenas com atribuições consultivas, a grande mobilização os tornou produtivos, e, posteriormente, eles foram incorporados ao sistema de gestão daqueles Estados.

A Associação Brasileira de Recursos Hídricos (ABRH) mobiliza-se e produz, com grande repercussão no meio técnico, as Cartas de Salvador em 1987 e de Foz do Iguaçu em 1989. Ambas conclamam a criação de um sistema organizado de gestão, e, em particular, a Carta de Foz do Iguaçu delineia os princípios básicos que deveriam ser seguidos no estabelecimento da Política Nacional de Recursos Hídricos. São eles, por exemplo, a gestão integrada, a bacia como unidade de gestão, o reconhecimento do valor econômico da água e gestão descentralizada e participativa.

Em 1989, numa iniciativa pioneira, algumas cidades das bacias dos rios Piracicaba e Capivari unem-se para formar o Consórcio Intermunicipal das Bacias dos Rios Piracicaba e Capivari, com o objetivo de promover a recuperação ambiental dos rios, a integração regional e o planejamento do desenvolvimento da bacia. É uma atitude inovadora por ter nascido na administração local e por prever um plenário de entidades, em que a sociedade civil é convidada a participar no processo de tomada de decisão.

A Lei n. 9.433, de 8.1.1997, que deu ao Brasil uma nova política de recursos hídricos e organizou o sistema de gestão, concretizou então a gestão por bacias 
hidrográficas. Hoje no Brasil, os recursos hídricos têm sua gestão organizada por bacias hidrográficas em todo o território nacional, seja em corpos hídricos de titularidade da União ou dos Estados. Há certamente dificuldades em se lidar com esse recorte geográfico, uma vez que os recursos hídricos exigem a gestão compartilhada com a administração pública, órgãos de saneamento, instituições ligadas à atividade agrícola, gestão ambiental, entre outros, e a cada um desses setores corresponde uma divisão administrativa certamente distinta da bacia hidrográfica.

O presente trabalho pretende apresentar o conceito de bacia hidrográfica, apresentar também o modo como o país encontra-se organizado para essa forma de gestão e discutir os principais pontos da gestão de recursos hídricos que estão associados a esse recorte geográfico. Abordam-se pontos difíceis da gestão integrada e a necessidade de aperfeiçoamento do sistema de decisão.

\section{Bacia hidrográfica: conceitos e definições}

A bacia hidrográfica é uma área de captação natural da água de precipitação que faz convergir o escoamento para um único ponto de saída. A bacia hidrográfica compõe-se de um conjunto de superfícies vertentes e de uma rede de drenagem formada por cursos de água que confluem até resultar em um leito único no seu exutório (Tucci, 1997).

A bacia hidrográfica pode ser então considerada um ente sistêmico. É onde se realizam os balanços de entrada proveniente da chuva e saída de água através do exutório, permitindo que sejam delineadas bacias e sub-bacias, cuja interconexão se dá pelos sistemas hídricos.

A questão da escala a ser utilizada depende do problema a ser solucionado. Pode ser delimitada a totalidade da bacia do Rio Amazonas, desde suas cabeceiras mais distantes na cordilheira andina até seu exutório do Oceano Atlântico, assim como podem ser delimitadas suas sub-bacias, maiores ou menores, dependendo da necessidade do problema a ser abordado. Diz-se que o tamanho ideal de bacia hidrográfica é aquele que incorpora toda a problemática de interesse. Pode-se ter interesse em uma pequena bacia de $0,5 \mathrm{~km}^{2}$ numa área urbana, como na bacia do Rio São Francisco, com mais de seus $600.000 \mathrm{~km}^{2}$ de área. Esse conceito sistêmico adapta-se muito bem aos sistemas de gestão de recursos hídricos.

Sobre o território definido como bacia hidrográfica é que se desenvolvem as atividades humanas. Todas as áreas urbanas, industriais, agrícolas ou de preservação fazem parte de alguma bacia hidrográfica. Pode-se dizer que, no seu exutório, estarão representados todos os processos que fazem parte do seu sistema. O que ali ocorre é conseqüência das formas de ocupação do território e da utilização das águas que para ali convergem.

\section{A divisão hidrográfica do território brasileiro}

O território brasileiro foi dividido num primeiro nível de macrodivisão hidrográfica, as chamadas Regiões Hidrográficas Brasileiras. A Resolução n.32 do Conselho Nacional de Recursos Hídricos, de 15 de outubro de 2003, define a divisão hidrográfica nacional em regiões hidrográficas como mostrado na Figura 1. 


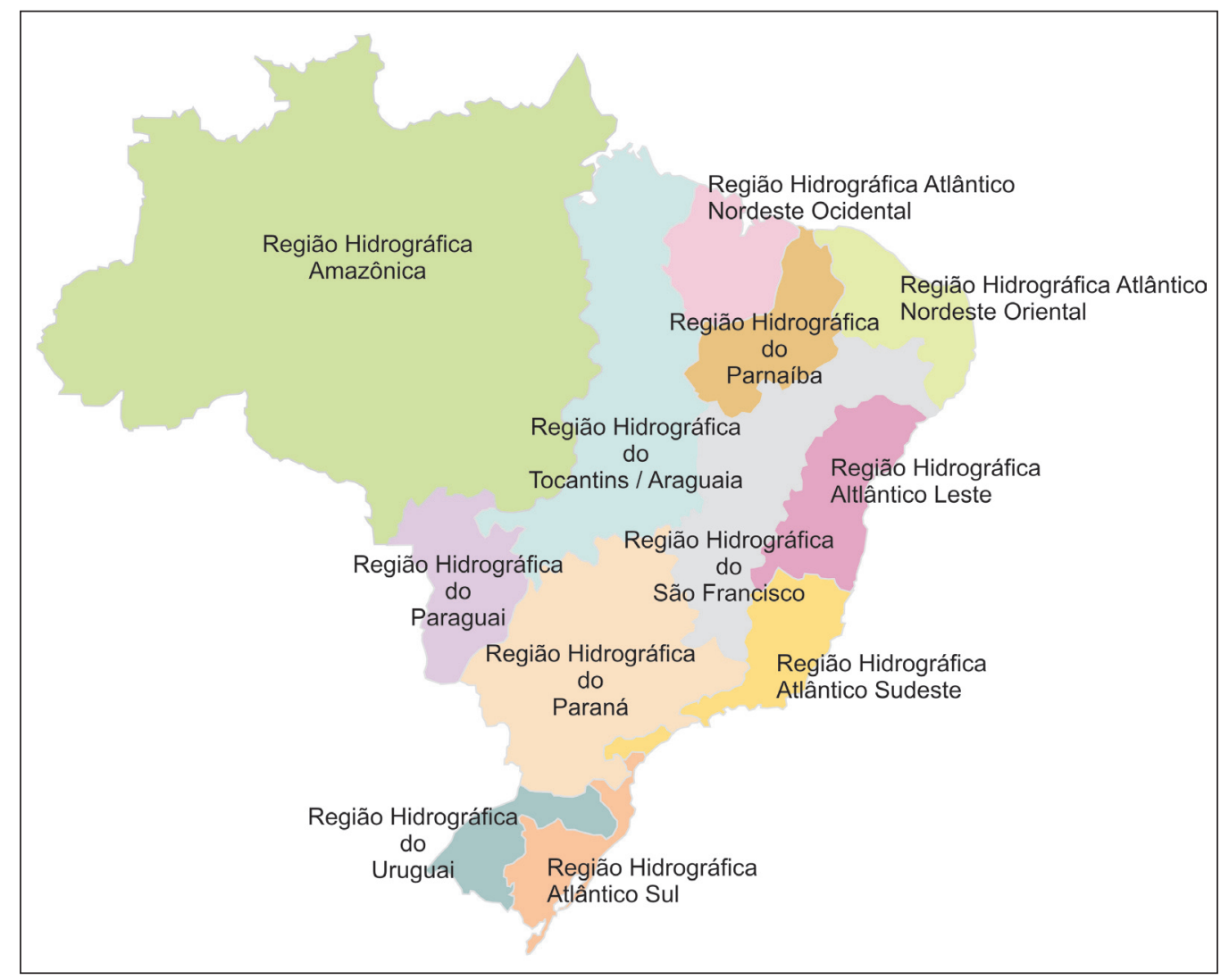

Fonte: CNRH (2003).

Figura 1 - Regiões hidrográficas brasileiras.

Essas regiões têm sua divisão justificada pelas diferenças existentes no país, tanto no que se refere aos ecossistemas como também diferenças de caráter econômico, social e cultural. A Tabela 1 mostra algumas dessas diferenças.

Os Estados brasileiros, no âmbito dos seus territórios, fizeram divisões hidrográficas para fins de gestão utilizando diferentes critérios. O Estado de São Paulo está dividido em 22 unidades de gestão hidrográficas; o Estado do Paraná, em 15; o Estado de Minas Gerais, em 36, e assim por diante.

O fato relevante está em poder ser reafirmado que tais divisões foram feitas de maneira a conformar as necessidades de gestão dos recursos hídricos com a configuração física e características locais.

\section{Aspectos legais e institucionais da gestão de bacias hidrográficas}

A Constituição de 1988 teve um importante papel para a gestão dos recursos hídricos. Definiu as águas como bens de uso comum e alterou a dominialidade das águas do território nacional, anteriormente definida pelo Código de Águas de 1934 (Decreto n.24.63, de 10.7.1934). O art. 20, inciso III, da Constituição Federal de 1988 indica, entre os bens da União, "os lagos, rios e quaisquer correntes de água em terrenos do seu domínio, ou que banhem mais de um Estado, sirvam de limites com outros países, se estendam a território es- 
Tabela 1 - Diferenças entre as regiões hidrográficas brasileiras

\begin{tabular}{l|c|c|c}
\hline \multicolumn{1}{c|}{ Região Hidrográfica } & $\begin{array}{c}\text { Vazão } \\
\text { média } \\
\left(\mathrm{m}^{3} / \mathrm{s}\right)\end{array}$ & $\begin{array}{c}\text { Densidade } \\
\text { demográfica } \\
1.000 \text { hab/km² }\end{array}$ & $\begin{array}{c}\text { Taxa de } \\
\text { urbanização } \\
(\%)\end{array}$ \\
\hline Região Hidrográfica Amazônica & 131.947 & 2 & $67 \%$ \\
\hline $\begin{array}{l}\text { Região Hidrográfica do Tocantins/ } \\
\text { Araguaia }\end{array}$ & 13.624 & 8 & $74 \%$ \\
\hline $\begin{array}{l}\text { Região Hidrográfica Atlântico Nordeste } \\
\text { Ocidental }\end{array}$ & 2.683 & 19 & $57 \%$ \\
\hline Região Hidrográfica do Parnaíba & 753 & 11 & $62 \%$ \\
\hline $\begin{array}{l}\text { Região Hidrográfica Atlântico Nordeste } \\
\text { Oriental }\end{array}$ & 779 & 75 & $76 \%$ \\
\hline Região Hidrográfica do São Francisco & 2.850 & 20 & $74 \%$ \\
\hline Região Hidrográfica Atlântico Leste & 1.492 & 36 & $70 \%$ \\
\hline Região Hidrográfica Atlântico Sudeste & 3.179 & 118 & $90 \%$ \\
\hline Região Hidrográfica Atlântico Sul & 4174 & 62 & $85 \%$ \\
\hline Região Hidrográfica do Uruguai & 4.121 & 22 & $68 \%$ \\
\hline Região Hidrográfica do Paraná & 11.452 & 62 & $91 \%$ \\
\hline Região Hidrográfica do Paraguai & 2.368 & 5 & $85 \%$ \\
\hline Fonte: MMA (2007). & & & \\
\hline
\end{tabular}

Fonte: MMA (2007).

trangeiro, ou dele provenham, bem como terrenos marginais e as praias fluviais".

No art. 26, inciso I, da Constituição Federal, incluem-se entre os bens dos Estados e do Distrito Federal “as águas superficiais ou subterrâneas, fluentes, emergentes e em depósito, ressalvadas, neste caso, na forma da lei, as decorrentes de obras da União".

Deve ser ressaltado que a dominialidade está definida sobre os corpos hídricos e não sobre a bacia hidrográfica, por essa se constituir em território e, portanto, estar sujeita a outros diplomas legais. Assim, para a gestão da bacia hidrográfica, exige-se, de fato, o exercício do princípio federativo, de atribuições e competências dos três entes federativos (União, Estados e municípios), visando à gestão compartilhada do bem de uso comum, a água.

Outra importante alteração introduzida pela Constituição Federal de 1988 foi a atribuição dada à União no seu art. 21, inciso XIX, para "instituir sistema nacional de gerenciamento de recursos hídricos e definir critérios de outorga de direitos de uso".

Esse artigo constitucional deu origem à Lei 9.433, de 8.1.1997, a qual instituiu a Política Nacional de Recursos Hídricos e criou o Sistema Nacional 
de Gerenciamento de Recursos Hídricos. A partir da aprovação dessa lei, o país passa a dispor de um instrumento legal que visa garantir às gerações futuras a disponibilidade do recurso hídrico. Concretiza-se a modernização do setor e a Lei n. 9.433 coloca o Brasil entre os países de legislação mais avançada do mundo no setor de recursos hídricos.

A Lei n. 9.433 tem entre os fundamentos da Política Nacional de Recursos Hídricos a água como um bem de domínio público, dotado de valor econômico, cujos usos prioritários são o abastecimento humano e a dessedentação de animais e cuja gestão deve tomar como unidade territorial a bacia hidrográfica. Prevê, como diretriz geral de ação, a gestão integrada, e como instrumentos para viabilizar sua implantação os planos de recursos hídricos, o enquadramento dos corpos de água em classes segundo os usos preponderantes, a outorga de direito de uso, a cobrança pelo uso da água e o sistema de informação sobre recursos hídricos e a compensação aos municípios.

O Sistema Nacional de Gerenciamento de Recursos Hídricos estabelecido pela Lei n. 9.433 deve cumprir os seguintes objetivos:

- coordenar a gestão integrada das águas;

- arbitrar administrativamente os conflitos ligados ao uso da água;

- implementar a Política Nacional de Recursos Hídricos;

- planejar, regular e controlar o uso, a preservação e a recuperação dos recursos hídricos;

- promover a cobrança pelo uso da água.

E integram o Sistema Nacional de Gerenciamento de Recursos Hídricos:

- o Conselho Nacional de Recursos Hídricos;

- os Conselhos de Recursos Hídricos dos Estados e do Distrito Federal;

- os Comitês de Bacia Hidrográfica;

- os órgãos de governo cujas competências se relacionem com a gestão de recursos hídricos;

- Agências de Água.

Em 2001 foi criada a Agência Nacional de Águas (ANA), de forma a complementar a estrutura institucional da gestão de recursos hídricos do país. É a entidade operacional do sistema com responsabilidade pela implantação da política nacional de recursos hídricos e que detém o poder outorgante de fiscalização e de cobrança pelo uso da água.

É interessante notar que esse sistema não exigiu a criação de uma nova e pesada estrutura administrativa, mas sim, e continua exigindo, um esforço bastante grande de articulação entre instituições já existentes. Apenas as Agências de Água seriam as novas estruturas administrativas a serem criadas. O objetivo é promover a descentralização da gestão, saindo de uma estrutura centralizada e permitindo que a decisão seja tomada na bacia hidrográfica. 
Outra característica importante do sistema é a importância dada à participação pública. Há no sistema a garantia da participação de usuários e da sociedade civil em todos os plenários por ele constituídos, desde o Conselho Nacional de Recursos Hídricos até os Comitês de Bacia Hidrográfica. É a forma de dar legitimidade à decisão e é também a forma mais eficiente para garantir a implantação das decisões tomadas.

A Lei n. 9.433/97 é atual, avançada e importante para a ordenação do uso da água, mas implica mudanças importantes dos administradores públicos e dos usuários, já que agora precisam ser receptivos ao processo de parceria. Desde o processo de discussão da lei, percebia-se a dificuldade da colocação dessas diretrizes em prática. Um dos principais desafios está em vencer a tradição de decisões centralizadas rumo à gestão regida pelo princípio da subsidiariedade (MMA, 2007).

Um ponto importante que merece destaque sobre a dificuldade de implantação desse modelo de gestão descentralizada e compartilhada é o entendimento, que até ocorre com muita freqüência, de que a gestão social "substitui" o poder central. Ao poder central cabe a responsabilidade do disciplinamento e da garantia de uso do bem comum (MMA, 2007). À gestão social competem, de fato, a vigilância e a construção do pacto de sustentabilidade.

\section{A organização institucional da bacia hidrográfica}

As atividades dos usuários de água em uma bacia hidrográfica são competitivas e se acirram à medida que diminui a disponibilidade hídrica per capita. A forma de dar sustentabilidade e eqüidade a essa competição foi definida pela Lei n. 9.433/97 e ela se dá por meio da instância de decisão local que são os Comitês de Bacia Hidrográfica.

Gerenciar essa competição significa criar um conjunto de regras para a alocação da água, o que, em última instância, é a essência do sistema de gestão de recursos hídricos. Para que o conjunto de regras seja criado, são necessários os instrumentos de gestão que as institucionalizam e a criação da instância de decisão local.

Pela Lei n. 9.433/97, essa instância de decisão é denominada Comitê de Bacia Hidrográfica, por meio da qual a decisão é trazida para o nível local. Em razão do caráter sistêmico do conceito de bacia hidrográfica, a Lei n. 9.433/97 deixou que as bacias, na forma de unidades de gestão, fossem definidas caso a caso, dando a possibilidade de conformá-las de acordo com a escala e as características da problemática local.

A Lei n. 9.433/97 define apenas as atribuições dos Comitês de Bacia Hidrográfica, estando entre elas as obrigações de articulação entre os diversos agentes, a atuação em primeira instância em caso de conflito, a aprovação do plano de recursos hídricos e a aprovação da implantação da cobrança e da proposta de preço.

Pode-se perceber que são atividades essencialmente de articulação e construção de consensos. Os comitês de bacia têm em sua composição, embora em 
diferentes partições do número de assentos dependendo da titularidade das águas, membros dos diversos níveis de governo, dos agentes privados e da sociedade civil. Sabe-se que as decisões que saem do consenso formam pactos e tendem a ser mais sustentáveis, mas sabe-se também que são mais demoradas. Buscam-se soluções que contemplem de forma satisfatória os interesses dos diversos agentes envolvidos e isso é parte do processo de negociação.

É preciso se ter claro que esse processo não cumpre, necessariamente, a necessidade de integração para a gestão. A integração se dará quando a decisão tomada e implantada contemplar os múltiplos aspectos da gestão das águas. Isso se dá, portanto, numa etapa posterior à da decisão participativa.

Nesse aspecto, há um longo caminho a ser trilhado. O bom funcionamento e a decisão qualificada dependem de capacitação e de bons sistemas de informação, ambos, infelizmente, quase sempre ausentes nos comitês em funcionamento no Brasil.

\section{Os instrumentos de gestão aplicados no contexto da bacia hidrográfica}

Uma gestão sustentável dos recursos hídricos necessita de um conjunto mínimo de instrumentos principais: uma base de dados e informações socialmente acessível, a definição clara dos direitos de uso, o controle dos impactos sobre os sistemas hídricos e o processo de tomada de decisão.

Dentre as principais inovações introduzidas pela Lei n. 9.433/97 está o estabelecimento claro, quase didático, dos instrumentos que devem ser utilizados para viabilizar a implantação da Política Nacional de Recursos Hídricos:

I os Planos de Recursos Hídricos;

II o enquadramento dos corpos de águas em classes de usos preponderantes;

III a outorga de direitos de uso dos recursos hídricos;

IV a cobrança pelo uso dos recursos hídricos;

V a compensação aos municípios;

VI Sistema de Informações sobre Recursos Hídricos.

Em termos práticos, os sistemas de gestão dependem de instrumentos que possam ser desenvolvidos e aplicados de forma a atender às expectativas $\mathrm{e}$ aos desejos da comunidade, nos limites impostos pela aptidão natural das bacias hidrográficas, seja na perspectiva mais utilitarista seja para o atendimento de objetivos de preservação ambiental, idealmente na medida equilibrada que é requerida para a garantia da sustentabilidade, no médio e no longo prazos.

Apenas com a plena e concreta aplicação dos instrumentos de gestao é que se pode avaliar se o sistema de gestão está implantado e qual seu grau de eficácia. Assim, não obstante os estágios avançados de desenvolvimento tecnológico, é fundamental tornar operacionais - até mesmo em termos institucionais - os sistemas e seus respectivos instrumentos de gestão, ou seja, mecanismos de decisão 
que sejam de aplicação viável e eficiente. Seja qual for a sofisticação dos modelos conceituais ou as perspectivas regentes dos sistemas (preservacionista ou utilitarista), a "operacionalidade" da gestão será definida a partir de um conjunto flexível e competente de instrumentos.

Outro detalhe que vale a pena ser lembrado é que a Lei n. 9.433/97 não obriga a aplicação de todos os instrumentos de gestão a todas as bacias hidrográfica nem limita que os instrumentos de gestão utilizados possam ser apenas estes. Por exemplo, é discutível a aplicação do instrumento de cobrança pelo uso da água aos rios da região amazônica, mas talvez bacias muito críticas, como o Alto Tietê, em São Paulo, necessitem de mais instrumentos de incentivo a boas práticas do que aqueles listados na lei. Esse é um dos pontos fortes da lei, pois permite adaptar a gestão às particularidades de cada bacia hidrográfica.

Os instrumentos de gestão possuem objetivos de aplicação distintos e devem ser utilizados para alcançar diferentes fins. Por exemplo, há instrumentos de disciplinamento (outorga), há instrumentos de incentivo (cobrança) e há instrumentos de apoio (sistemas de informação). Esses, com suas respectivas facilidades/dificuldades e vantagens/desvantagens, não são excludentes entre si. Embora não seja trivial sua implantação conjunta e de modo articulado, a maior eficácia certamente virá da aplicação conjunta dos diversos instrumentos, utilizando-os de acordo com sua potencialidade para melhor resolver o problema em questão (Porto \& Lobato, 2004a, b).

Os dois primeiros instrumentos indicados pela Lei n. 9.433/97 têm por objetivo a construção de consensos na bacia hidrográfica. São eles o Plano de Recursos Hidricos e o Enquadramento de Recursos Hidricos. São instrumentos que ampliam as possibilidades do planejamento tradicional, mediante processos participativos de construção de consensos, abrindo espaços para inserção da sociedade civil e de agentes econômicos com interesses particulares (públicos e privados) em tais processos de negociação.

A perspectiva assumida é a da construção de pactos no que se refere à definição de objetivos e o estabelecimento de consensos sobre os cenários desejados, em termos de viabilidade econômica, qualidade ambiental e do correspondente rateio de custos sociais. Os planos de recursos hídricos, definidos no âmbito de comitês de bacia hidrográfica, constituem bons exemplos dos processos de negociação social. Da mesma maneira, a negociação que leva ao enquadramento dos corpos hídricos permite uma melhor explicitação da relação entre usos da água e objetivos de qualidade pretendidos, atrelados aos custos de investimento necessários para atingi-los.

Esses dois instrumentos possuem papel bastante relevante numa das fronteiras de integração mais difíceis para a gestão de recursos hídricos que é sua articulação com a gestão territorial. Ao serem definidas as aptidões da bacia hidrográfica em seu plano e os objetivos de qualidade da água, haverá, por conseqüência, um direcionamento da gestão territorial, pois algumas atividades po- 
derão ser incentivadas e outras reprimidas, seu impacto sobre os recursos hídricos.

O terceiro instrumento de gestão citado na lei é um dos mecanismos clássicos de Comando\&Controle: a outorga de direito de uso da água. Como dito anteriormente, as águas são todas de domínio público no Brasil. Portanto, toda a utilização de recursos hídricos está sujeita à obtenção de outorgas de direitos de uso, na forma de uma autorização condicionada de uso, emitida pela União ou pelos Estados, a depender da dominialidade do corpo hídrico a ser explorado. A exceção, prevista na própria legislação, são os usos considerados como insignificantes, isentos da obrigatoriedade de obtenção de outorgas, mas definidos localmente em cada bacia hidrográfica e pelos respectivos comitês, em função das disponibilidades hídricas e demandas.

É importante destacar que a outorga representa o poder disciplinador do poder público para atender à sua obrigação de fazer valer a eqüidade entre os usuários da água. Constitui direito intransferível do poder público, o qual dá aos usuários a autorização formal, inalienável, para uso de recursos hídricos, por prazos preestabelecidos.

É mediante o conhecimento das disponibilidades hídricas (redes de monitoramento hidrológico) e do cadastramento das demandas (usos e usuários outorgados) que o poder público reúne condições de controle e gestão da água, a ser efetuada em duas vertentes: (i) o controle do uso, relativo ao usuário; e, (ii) o controle de objetivos de gestão, voltado ao corpo hídrico (Leal, 1998).

Para que tais controles sejam exercidos, os órgãos públicos responsáveis devem estar bem organizados e equipados, tanto em relação à base de dados e informações necessárias quanto em relação às estruturas de fiscalização e monitoramento, de modo a assegurar que os condicionantes estabelecidos durante o procedimento de outorga estejam sendo respeitados.

Apesar de esse instrumento ser tipicamente do tipo Comando\&Controle, a utilização conjunta e articulada de todos os instrumentos de gestão permite sua mescla com os instrumentos de consenso anteriormente apresentados, na medida em que os critérios utilizados para a concessão de outorgas podem ser amplamente discutidos e obtidos por consenso nos planos de recursos hídricos.

Além disso, a outorga pode ser também utilizada como um instrumento de implantação de sistemas de gestão de demanda e uso racional da água, além de permitir que se faça o disciplinamento do tipo de atividade a ser implantada na bacia e, portanto, também auxiliar na gestão territorial.

$\mathrm{O}$ quarto e o quinto instrumentos previstos na lei são a cobrança pela utilização dos recursos hídricos e a compensação aos municípios. Ambos são instrumentos de incentivo econômico à gestão adequada dos recursos hídricos. São incentivos descentralizados que orientam os agentes a valorizarem os bens e serviços ambientais, de acordo com sua oferta e/ou escassez. 
Em 1972, a Organização para a Cooperação Econômica e Desenvolvimento recomendou a utilização do princípio do "poluidor-pagador". Esse princípio expressa a noção de que os custos derivados da poluição (externalidades ambientais) devem ser internalizados pelos próprios agentes que os causaram. Não se trata de simples compensação pelo dano. O princípio indica que o poluidor deve pagar pelos custos de prevenção da poluição e, também, por programas que incluam medidas de gestão da qualidade da água. O princípio do "poluidor pagador" deve combinar requisitos de eficiência (internalização dos efeitos ambientais externos) e de eqüidade social (paga mais quem tem maior responsabilidade pela poluição) (OECD, 1972).

O mesmo conceito vale para o usuário-pagador. A utilização de uma quantidade inadequada de água causará externalidades ambientais e ineqüidade social. Por essas razões, a Lei n. 9.433/97 prevê a cobrança pelo uso da água tanto para captações e derivações como para lançamento de efluentes.

A aplicação dos instrumentos econômicos deve ser feita de forma a evitar que eles sejam "percebidos" pelos usuários-pagadores como meros impostos ou penalidades associadas aos mecanismos tradicionais de Comando\&Controle. A forma de evitar que isso aconteça é buscar que esse instrumento seja "construído" dentro do sistema de forma compartilhada, com ampla discussão sobre sua aplicação e sobre a definição adequada dos preços (Porto \& Lobato, 2004a, b). Deve-se reconhecer que é difícil para o usuário perceber a diferença entre o preço como mecanismo de incentivo e como mecanismo de arrecadação.

A forma mais comum de aplicação desse instrumento é implementá-lo atrelado a um conjunto de medidas de caráter de Comando\&Controle, a exemplo da outorga. A cobrança constitui um incentivo econômico para que um determinado objetivo de uso racional ou qualidade da água seja atingido. Novamente, vê-se aqui o potencial sinérgico da aplicação conjunta de mecanismos de gestão. Os mecanismos econômicos têm o poder de aumentar a eficiência dos mecanismos de Comando\&Controle pelo incentivo de preço, o qual induz um comportamento, por parte do usuário, de maior conformidade à gestão sustentável da bacia.

O mecanismo de compensação a municípios, apesar de ter tido os artigos a ele dedicados na Lei n. 9.433/97 vetados, não foi eliminado como instrumento de gestão. Esse mecanismo é essencial, pois permite fazer a ligação entre os pontos críticos para a gestão das bacias hidrográficas, como dito anteriormente, que são a gestão dos recursos hídricos e a gestão territorial. A Constituição Federal deixou a gestão territorial quase que integralmente para apenas um dos entes federados que é o município. É muito difícil, portanto, haver interferência do setor de recursos hídricos sobre a questão da ocupação do território. A única forma de intervir é por meio de mecanismos de incentivo. Esse instrumento tem sido pouco utilizado, ignorado até, mas pode ser de grande valia, pois há várias maneiras de incentivar os municípios a desenvolverem atitudes em conformidade com a sustentabilidade da bacia. Os municípios devem ser incentivados a 
ter melhores planos diretores de uso e ocupação do solo, de modo a preservar várzeas e outras áreas sensíveis. Devem também ser incentivados a incorporar em seus códigos de edificação práticas que induzam ao uso racional da água e ao controle de impermeabilização nas construções e empreendimentos. Há diversos exemplos no país do ICMS ecológico, como no Estado do Paraná, o Município Verde em São Paulo, entre outros. Há também mais uma possibilidade de integração dos instrumentos que é a aplicação dos recursos arrecadados pela cobrança da água a esses incentivos.

O sexto instrumento, sistemas de informação, é a base essencial para a correta aplicação de todos os demais instrumentos de gestão. A decisão informada é uma decisão mais bem qualificada. A gestão de bacias hidrográficas envolve uma grande quantidade de aspectos sociais e políticos, e muitas vezes tal característica induz a uma avaliação equivocada do que seja a "missão de gerir". O objetivo último do processo de gestão é tomar decisões sobre o uso dos recursos hídricos de uma bacia e implementá-las com eficácia. Por mais importantes que sejam os fatores de natureza social, como a participação pública, a realização de campanhas de orientação, a promoção de programas de educação ambiental e outras, é inescapável que decisões de boa qualidade dependam de informações e de ferramental analítico para lhes dar suporte. Por essa razão, o Sistema Nacional de Recursos Hídricos cita explicitamente os Sistemas de Informações como um de seus instrumentos de gestão.

Em última análise, o processo de gestão exige ferramentas computacionais que permitam o acesso rápido aos dados da bacia hidrográfica, possibilitem a avaliação de cenários atuais e futuros e possam analisar alternativas de implantação de obras e/ou de operação de sistemas. Tomadas de decisão sobre outorga, eventuais racionamentos, enquadramento de cursos de água por classes de uso, controle de cheias, tratamento e diluição de efluentes, adoção de medidas de contingência e outras não podem prescindir de bases de informações sistematicamente organizadas e atualizadas. Há um grande esforço para a criação do Sistema Nacional de Informação em Recursos Hídricos que vem sendo desenvolvido pela Agência Nacional de Águas, e vários Estados da Federação vêm também investindo em seus sistemas estaduais.

Há outros conjuntos de instrumentos de gestão possíveis e que podem ser aplicados pelos comitês de bacia hidrográfica. Por exemplo, há mecanismos chamados de adesão voluntária que buscam conformidade por razões externas ao processo de comando e controle. Recentemente tem havido um grande esforço por parte do setor industrial com a busca de conformidade ambiental relativa à série ISO 14000 como forma de acesso a mercados compradores mais exigentes. Essa via tem demonstrado importante capacidade de espraiar os padrões ambientais exigidos nos principais mercados mundiais (notadamente, Europa e Estados Unidos) até os parques produtivos dos demais países, reunindo méritos de promover incentivos à modernização tecnológica e à redução de rejeitos, considerados como desperdícios dos processos produtivos. 
Para o sistema de gestão de recursos hídricos, é de interesse também que, na perspectiva de médio e longo prazos, seja criado um sistema capaz de atrair os usuários ao atendimento voluntário das metas propostas. Esse sistema pode ser visto como uma adesão gradativa às metas, incentivada mediante acesso facilitado a recursos disponíveis na bacia e, quando cabível, desconto na cobrança pelo uso da água.

A aplicação das diretrizes passíveis de adesão progressiva será definida sobre objetos de gestão compartilhada que venham a ser estabelecidos no âmbito de competências comuns entre Estado e municípios. São objetos de gestão compartilhada os componentes das políticas e programas de drenagem urbana, resíduos sólidos, abastecimento de água (incluindo medidas de conservação e uso racional), esgotamento sanitário, preservação de mananciais, uso e ocupação do solo e outras.

O grande desafio dos planos de bacia é harmonizar as condutas dos diferentes agentes, nas esferas estadual - órgãos da administração e concessionários - e municipal, que têm responsabilidades no aproveitamento de recursos hídricos, além, é claro, dos agentes privados. Formas incentivadas de adesão de todo o conjunto de agentes (e não somente dos municípios, conforme previsto no instrumento econômico citado anteriormente) podem trazer grandes benefícios à gestão integrada da bacia hidrográfica.

\section{O processo decisório: Sistemas de Suporte a Decisões}

Em primeiro lugar, é necessário o entendimento comum sobre os conceitos e significados de dados, informações e sistemas de suporte a decisões e sua importância para o processo de tomada de decisões.

Entende-se por dado o registro de algo importante para as atividades de gestão de recursos hídricos. É essencial que os dados sejam armazenados de forma segura e íntegra, e possam ser facilmente recuperáveis. Para tanto, há necessidade de utilização de programas de computador especializados (os chamados bancos de dados) e é essencial a existência de um responsável (ou responsáveis) pela atualização e manutenção desses sistemas.

Informação é o dado ao qual se atribui um significado. Dados não costumam ser importantes para o processo decisório, mas informações são essenciais. A transformação de dados em informações pode ser um processo simples de análise comparativa ou adição de conhecimentos correntes, mas poderá requerer análises mais elaboradas com a utilização de modelos matemáticos.

Sistemas de suporte a decisões podem ser entendidos como processos ainda mais elaborados e complexos da transformação de dados em informações. Esses sistemas costumam agregar grandes bases de dados de diversas naturezas, além de utilizar diversos modelos para construir cenários e analisar cenários com a finalidade última de propiciar a tomada de decisões de melhor qualidade.

Os Sistemas de Suporte a Decisões (SSD) constituem uma metodologia de auxílio à tomada de decisão baseada na intensa utilização de bases de dados 
e modelos matemáticos, bem como na facilidade com que propiciam o diálogo entre o usuário e o computador. Diversos problemas em que a questão da tomada de decisões é muito complexa, como é o caso do gerenciamento e do planejamento de sistemas de recursos hídricos, vêm sendo enfrentados com sucesso com a utilização dessa metodologia.

Quando se dispõe de um SSD, o usuário conta com um instrumento potente para auxiliá-lo a dispor de informações, a identificar e formular problemas, a conceber e analisar alternativas e, finalmente, a ajudá-lo na escolha do melhor curso de ação. Em outros termos, a finalidade de um SSD não é tomar decisões, mas auxiliar a missão de decidir. A Figura 2 mostra a estrutura típica de um Sistema de Suporte a Decisões.

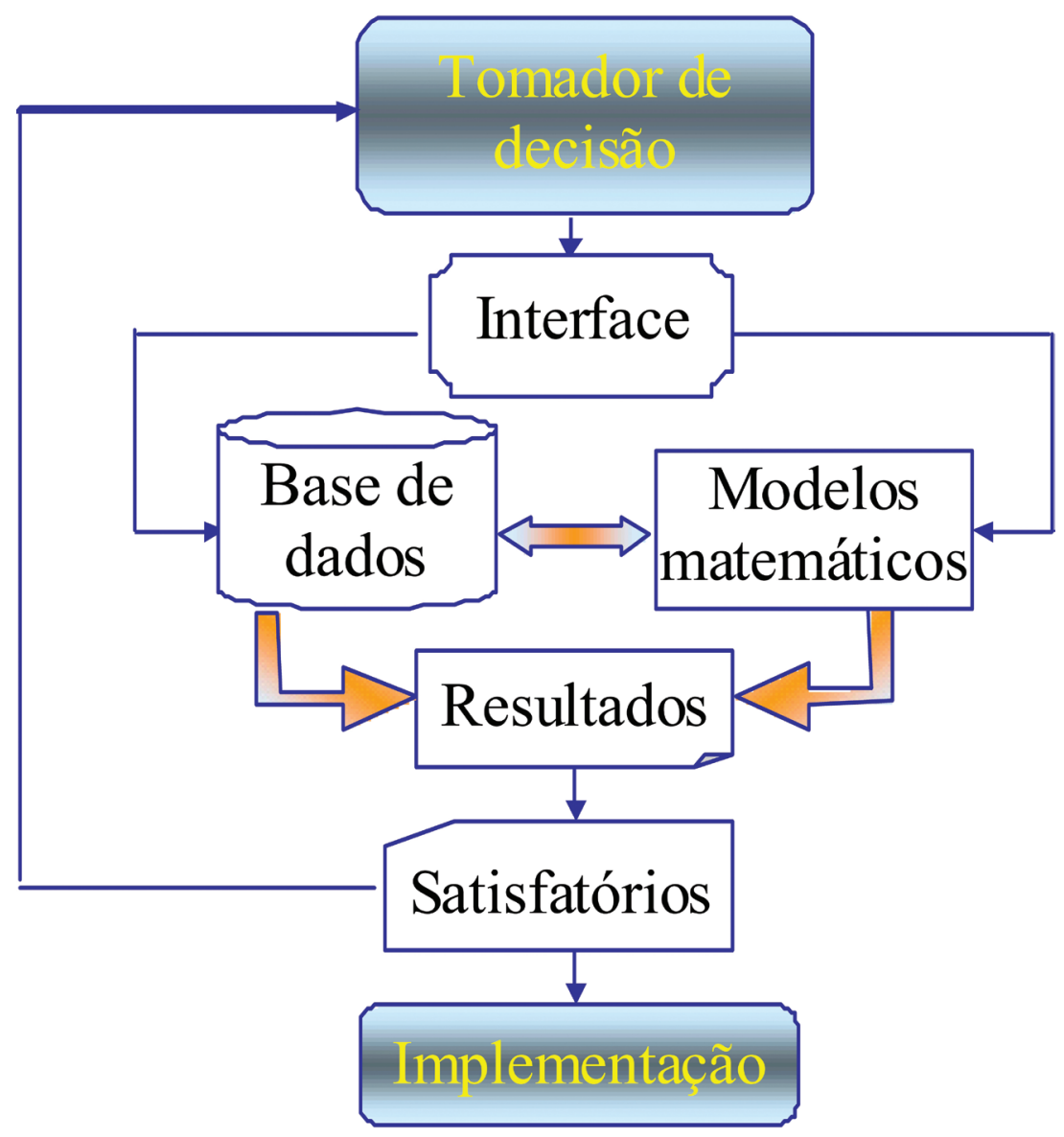

Figura 2 - Estrutura típica de um Sistema de Suporte a Decisões.

A função dos diversos componentes da estrutura de um SSD pode ser resumida como segue:

(i) a Base de Modelos é geralmente constituída por modelos matemáticos que reproduzem o comportamento do sistema real, permitem analisar cenários 
alternativos (modelos de simulação) e ajudam o usuário a encontrar dimensões ou políticas ótimas de operação (modelos de otimização). A missão essencial dos modelos é transformar dados em informações de boa qualidade;

(ii) a Base de Dados, além de conter informações significativas sobre o sistema em questão, deve permitir relacioná-las entre si e recuperá-las com facilidade e rapidez. Esse módulo deve também alimentar a Base de Modelos com os dados necessários e armazenar os resultados dos modelos para futuras análises e comparações;

(iii) o Módulo de Diálogo é constituído por interfaces que facilitam a comunicação entre o usuário e o computador para fornecer dados, propor problemas, formular cenários e analisar resultados. A evolução dos microcomputadores e o surgimento das linguagens de programação por objeto ocasionaram verdadeira revolução nesse campo. Atualmente, o diálogo com o usuário pode ser simples, intuitivo e rico em recursos de comunicação (gráficos, fotografias, animação, som, realidade virtual etc.). A importância desse módulo é inestimável, pois facilita a participação de não-especialistas no processo de avaliação e tomada de decisões.

A experiência tem mostrado que Sistemas de Suporte a Decisões são instrumentos eficientes para auxiliar os chamados Grupos de Tomada de Decisões. Nesses grupos, as naturais diferenças de ponto de vista, interesses, ideologias e formação dos participantes costumam dificultar, e em algumas vezes impossibilitar, a escolha dos melhores cursos de ação.

A idéia central, nesse caso, é permitir que cada um dos participantes avalie as conseqüências da implementação de suas idéias com o auxílio de modelos aceitos por todos, a partir de uma base comum de informações. Começam a surgir, a partir daí, as oportunidades de soluções negociadas que tendem a contar com o apoio e o comprometimento de todo o grupo, ressaltando que o sistema de gestão de recursos hídricos brasileiro foi construído com o propósito de ser descentralizado, integrado e, especialmente, participativo. Para tanto, foram criados os comitês de bacia hidrográfica com a presença dos setores de governo, dos técnicos, dos usuários e da sociedade civil.

Essa estrutura é o que legitima o sistema e dá forças para sua sustentação. No entanto, para que o sistema evolua, torna-se necessário que o processo participativo de discussão e de integração entre os setores de governo, técnicos e usuários desses recursos mantenha os canais de diálogo abertos. Em outras palavras, é necessário que os responsáveis pela decisão e a sociedade consigam administrar seus conflitos em sistemas extremamente complexos, como é o caso do gerenciamento de recursos hídricos.

Nesse ambiente de complexidade, interesses divergentes e até mesmo valores e ideais distintos é que os Sistemas de Suporte a Decisões encontram as maiores possibilidades de realização de seus objetivos. 


\section{Conclusão}

A Lei n. 9.433/97 iniciou a implantação da gestão integrada das águas no Brasil. Esse conceito, apesar de amplamente aceito, é de alta complexidade e encontra inúmeras dificuldades para sua implantação. O conceito de descentralização da gestão para o nível local e as necessidades de articulação que a gestão por bacias hidrográficas exige estão ainda dependentes de uma enorme evolução institucional do país. A contribuição essencial dessa lei para o país é sua contribuição para um novo paradigma de gestão de um bem de uso comum, cuja má administração pode trazer efeitos bastante perversos para toda a sociedade brasileira.

Entre essas dificuldades, estão a efetiva descentralização para o nível local da bacia hidrográfica (gestão compartilhada) e necessidade de articulação entre os dois níveis de dominialidade previstos na Constituição Federal.

Há que levar em consideração, no entanto, que os instrumentos de gestão podem auxiliar na construção dos mecanismos de gestão compartilhada. Não há um recorte geográfico que seja ideal para todos os agentes que participam do processo. A vantagem da utilização do recorte por bacia hidrográfica está em que, ao menos, este guarda relação física direta com a água, que é o bem objeto desta gestão.

No mais, as dificuldades podem e devem ser enfrentadas. O país avançou muito na aplicação dos instrumentos de gestão. Hoje já há maturidade para se perceber, por exemplo, que os mecanismos de comando e controle são atrativos e apresentam boa eficácia durante os períodos iniciais do processo de gestão da bacia. Entretanto, à medida que os problemas a serem atacados tornam-se mais complexos, os instrumentos baseados somente nos conceitos de comando e controle tendem a se esgotar, e a gestão precisa apoiar-se em instrumentos de aplicação mais difícil, como são os mecanismos econômicos, em outros mais caros, como os sistemas de informação.

Resta ainda chamar a atenção para o principal problema de articulação que é gestão territorial. Esse também é um problema sério para a gestão de bacias hidrográficas, mas que encontra bastante espaço para sua viabilização se apoiado de forma criativa nos instrumentos de gestão previstos na Lei n. 9.433/97.

\section{Nota}

1 O instrumento de gestão apontado na Lei n. 9.433/97 é denominado Plano de Recursos Hídricos. É assim denominado de modo genérico por não se referir apenas a planos de bacia. São parte desse mesmo instrumento o Plano Nacional de Recursos Hídricos e os Planos Estaduais de Recursos Hídricos. Neste trabalho está se buscando examinar sua aplicação às bacias hidrográficas e daí o comentário que tal instrumento permite a construção do consenso no âmbito da bacia. Na verdade, o instrumento permite a construção do consenso no nível de sua aplicação. 


\section{Referências bibliográficas}

CNRH. Resolução n. 32, de 15 de outubro de 2003. Anexo I. Conselho Nacional de Recursos Hídricos. Brasília, DF: Ministério do Meio Ambiente, 2003.

DOUROJEANNI, A. Management procedures for sustainable development. Serie $\mathrm{Me}$ dio Ambiente y Desarrollo n.3. Santiago, Chile: Economic Commission for Latin America and the Caribbean, United Nations, 1997.

GRANZIERA, M. L. M. Direito de águas: disciplina jurídica de águas doces. São Paulo: Atlas, 2001.

GRIGG, N. S. Delph Carpenter, Father of Colorado River Treaties: Text of Governor Ralph L. Carr's 1943 Salute to Delph Carpenter. Fort Collins: Colorado Water Resources Research Institute, 1991.

LEAL, M. S. Gestão ambiental de recursos hidricos: princípios e aplicações. Rio de Janeiro: CPRM, 1998.

MMA. GEO Brasil: Recursos Hidricos. Brasília: Ministério do Meio Ambiente; Agência Nacional de Águas; Programa das Nações Unidas para o Meio Ambiente, 2007.

OECD. The Polluter-Pays Principle. Paris: Organization for Economic Co-operation and Development, 1972.

PORTO, M. F. A.; LOBATO, F. Mechanisms of Water Management: Command \& Control and Social Mechanisms. Revista de Gestion Del'Agua de America Latina, v.2, p.113-29, 2004a.

. Mechanisms of Water Management: Economics Instruments and Voluntary

Adherence Mechanisms. Revista de Gestion Del'Agua de America Latina, v.1, p.132$46,2004 b$.

TUCCI, C. E. M. 1997. Hidrologia: ciência e aplicação. 2.ed. Porto Alegre: ABRH/ Editora da UFRGS, 1997. (Col. ABRH de Recursos Hídricos, v.4).

WMO. The Dublin Statement and Report of the Conference. International Conference on Water and the Environment: Development Issues for the 21 $1^{\text {st }}$ Century. 26-31 January 1992. Dublin, Ireland.

YASSUDA, E. R. Gestão de recursos hídricos: fundamentos e aspectos institucionais. Rev. Adm. Púb., v.27, n.2, p.5-18, 1993.

RESUMO - O presente trabalho pretende apresentar o conceito de bacia hidrográfica, apresentar também o modo como o país encontra-se organizado para essa forma de gestão e discutir os principais pontos da gestão de recursos hídricos que estão associados a esse recorte geográfico. Abordam-se pontos difíceis da gestão integrada e a necessidade de aperfeiçoamento do sistema de decisão.

PALAVRAS-CHAVE: Gestão de recursos hídricos, Gestão integrada, Bacias hidrográficas. 
ABSTRACT - This paper presents the concept of watershed management and how water resources management in Brazil evolved to implement local institutions. There are several restrictions and difficulties related to this form of local management and they will be discussed here, especially those linked to the integration of this administrative division to other units such as municipalities, for example.

KEXWORDS: Water resources management, Integrated management, Watershed management.

Monica F. A. Porto e Rubem La Laina Porto são professores da Escola Politécnica da Universidade de São Paulo. @-mporto@usp.br e rlporto@usp.br

Recebido em 17.6.2008 e aceito em 23.6.2008. 